\title{
Information Literacy and Collaborative Practice through Project Based Learning: Experiences of First Year Teacher Candidates
}

\author{
Dennis A. Conrad ${ }^{1}$, Elna Carrington-Blaides ${ }^{2}$ \\ ${ }^{1}$ State University of New York at Potsdam, USA \\ ${ }^{2}$ University of the West Indies, Trinidad and Tobago \\ conradda@potsdam.edu,elnacarringtonblaides@yahoo.com
}

\begin{abstract}
This paper explores the perceptions and experiences of first year pre-service teacher candidates regarding collaborative project-based learning. The project involved the creation and management of campus wide informative exhibits that address disability-specific inclusive practice. Results indicated a strand of pervasive resistance and other challenges related to communication, scheduling and work ethic, school culture, and precollege experiences. Respondents shared a need for leadership and advocacy development
\end{abstract}

\section{Introduction}

Education remains a key factor for social and economic mobility in the Caribbean, and more specifically in Trinidad and Tobago. Yet some might contend that there appears to be an entrenched and pervasive elitism that challenges an adequate and socially just education, particularly for those with academic difficulties or at risk of difficulties because of exceptionality, poverty, or other untenable circumstances. A subsequent pervasive elitism and individualism presents considerable constraints for the stated mission of the government to a seamless and inclusive education system. 'Seamless' refers to the Government's mission and plan, supported by a loan from the Inter-American Development Bank (ADB), for quality and equitable education for all from early childhood. This seamless approach embraces children from disadvantaged families and school development efforts to meet the diverse needs of students while fostering lifelong learning. Seamless education relates to a notion of integrated efficiency aimed at removing barriers to learning and facilitating quality graduates and citizens. Minister Manning, as the Minister of Education in 2007, emphasized that a seamless education is based in the principles of diversity, and collaboration practice [1].

A key strategy towards the mission of seamless education is the emphasis on teacher education, and the recent role of the University of Trinidad and Tobago (UTT) in providing more teachers, namely pre-service teachers. Teacher preparation is expected to aggressively enhance efforts at addressing knowledge, pedagogical skills, and appropriate ideal moral qualities. These might involve addressing issues of social justice, advocacy, culturally responsive pedagogy, multicultural leadership and school reorganization [2].

Trinidad and Tobago's drive for seamless education hinges on inclusive education of children with or at risk of special needs into the regular education experiences from early childhood. However the reality is that most of these students are already in government and government assisted [primarily parochial] schools, often ignored or dependent on the individual teacher's philosophy, commitment and professionalism. Further the culture of teacher education is resistant to co-teaching as classrooms are most often separated by chalkboards and classroom control is more evident than classroom management. As such teachers generally while collegial tend to limit themselves to their own students.

Of importance is the preparedness of teachers and teacher-candidates to work collaboratively with other. Each educator is going to be increasingly assigned responsibilities to provide services for children with or at risk of special needs. Teachers are going to be recruited with the expectation that they can work cooperatively with the special educators and support services to effectively accommodate all students. Special educators will find themselves with changing roles and responsibilities that extend to working collaboratively with regular education teachers and administrators to solve problems and develop interventions. This collaborative emphasis facilitates a more naturalistic teaching/learning environment, characterized increased benefits for all children. Teachers too will be more cognizant of their strengths, challenges, and resources as they work collaboratively to address the unique needs of students. 
The respondents in this paper are all undergraduate teacher candidates. Some may go on to special education as their major. It is part of the mission of UTT's School of Learning, Cognition, and Education to sensitize ALL teacher candidates to inclusive education practices through this course and related course-work.

\section{The Context}

Trinidad and Tobago [Trinbago] is a twin island republic in the southern Caribbean. It celebrates a rich multiculturalism, healthy economy, stable political environment within the democratic tradition, with educational opportunities for all. Trinbago's educational system originally fashioned from the British model is also influenced by US policies. The education system of Trinbago comprises government, government-assisted, and private institutions from pre- through to tertiary levels; with the Ministry of Science, Technology, and Tertiary Education, the Ministry of Education, and the Tobago House of Assembly as the key government agencies administering educational services.

Primary level education for children between the ages of six and twelve is compulsory. On average, beginning at age five, pupils begin two years of preparatory or "infant" standards [grades]; then complete five additional "standards" before going on to secondary schools. The structure of the secondary school system generally comprises two cycles: the first lasting five years leading to the Caribbean Examinations Council Secondary Education Certificate, and the second cycle lasting two years leading to the Caribbean Advanced Proficiency Examination. This is pre- university level.

The recently established University of Trinidad and Tobago (UTT) in 2004 is one of three tertiary level Trinidad and Tobago institutions providing teacher education. The other two institutions are the University of the Southern Caribbean (USC) and the University of the West Indies (UWI). USC includes an introductory course in Exceptional Learners in its undergraduate education programmes. Currently UWI offers a course at the postgraduate level, which is offered as a single course within its M. Ed in Youth Guidance. UWI is also actively involved in broadening course offerings for special and inclusive education

UTT, through its School for Studies in Cognition, Learning, and Education addresses teacher education through its pre-service B. Ed degree at two campuses, namely Valsayn and Corinth. The year 2011 will mark the graduation of its first cohort of teacher-candidates, with an expected 50 teacher candidates in special education.

\subsection{Theoretical Framework}

This paper, in exploring the collaborative experiences of pre-service teacher candidates involved in one project locates its theoretical framework within the intersection of information literacy, project based learning, constructivism, learning communities, and collaborative practice.

\subsubsection{Literacy Information}

UNESCO defines information literacy as the means one has to effectively identify, evaluate, use and create information to meet personal, social, occupational and educational goals [3]. Further, it asserts that information literacy is a basic human right that promotes social inclusion for all. According to the U.S. National Commission on Library and Information Science [4]. An important component of information literacy is information technology involving the appropriate use a variety of electronic tools $[5,6]$. There are five standards that guide an interpretation of information literacy, according to the Association of College and Research Libraries. These standards assert that the information literate student:

1) determines the nature and extent of the information needed

2) accesses needed information effectively and efficiently

3) evaluates information and its sources critically and incorporates selected information into his or her knowledge base and value system

4) individually or as a member of a group, uses information effectively to accomplish a specific purpose; and

5) understands many of the economic, legal, and social issues surrounding the use of information and accesses and uses information ethically and legally.

\subsubsection{Project Based Learning}

The skills associated with literacy information are critical to Project Based Learning (PBL) experiences. Participants are required to explore particular issues or problems be critical users of relevant information, and be creative producers of knowledge [7, 8. 9] Project-based learning organizes learning around problems or challenges that involve research, design, decision making, cooperative and other learning activities [10]. These, Holubova contends, might also involve activities outside the immediate classroom or context to include perspectives from all stakeholders [11].

The success of instructional goals in project based learning, according to Panasan and Nuangchalerm [12], is associated with perceptions of achievement, understanding of learning, studying habits, and collaborative practice. Larmer and 
Mergendoller, [13] building on Thomas, [14] stress the importance of projects being personally meaningful and meeting four key criteria: being necessary, involving a driving question that is compelling and purposeful, incorporating the voices of the participants, and intense collaborative and communicative practice. Marx et al [10] identify four primary benefits; namely the development of a rich, integrated understanding of content and process; learning to problem solve and collaborate, independent learning, and broader task development skills associated with the particular assignment. The overall success of project-based learning is recognizing that the task matters to participants; that they want to do well [13]; and that the project serves a meaningful educational purpose. Participants are encouraged to work independently towards the objectives of realistic presentations and/or products [14].

Within the Caribbean, one can assert that many students graduating high schools do not have key elements and experience of using information literacy and particularly information technology for project based Learning. This of course is not limited to the Caribbean, and evident in more developed countries [15], [16]. Indeed, Bowler et al [8] contend that technological illiteracy hampers effective student learning. Given the crucial role of information literacy and IT skills in modern society, educators must find ways of leading students towards gaining competency in these areas. The approach undertaken in this study has been shown to be a promising strategy for educators to aid students as young as primary school level toward becoming information literate and skilled in IT.

\subsubsection{Constructivist learning}

Self-constructed knowledge by learners, also referred to constructivism, has been shaped primarily by Dewey, Piaget, and Vygotsky [17, 18, 19]. Constructivist learning continues to positively influence teacher education, reflecting a shift from behaviourism to cognitive theory where curricula is designed for learning rather than planned for teaching [20].

The co-researchers posit that the creation and display of informational booths that advocate on behalf of issues of exceptionality characterize constructivist learning. Information used in these booths is gleaned from interaction and information through service organizations and perspectives of community leaders. This approach while facilitating active participation to address community needs, and encourage civic responsibility, provides time for critical reflective practice [21]. Schon [22] proposes this is a central characteristic of a professional practitioner.

In planning, developing, producing an evaluating the exhibition, pre-service teacher candidates--particularly are afforded opportunities that enhance content knowledge, pedagogical skills, self-confidence, respect for diversity, and sense of caring [25]. Dudderar and Tover's [25] contend that candidates using service learning activities as addressed through this project based approach are more likely: to have an increased commitment to using such practices in their teaching, and show an increase in altruism and other desirable ideal moral qualities. Learning is sustained social engagement situated and resulting in communities of practice

\subsubsection{Collaborative practice}

The collaborative process focuses on planning and problem solving for action aimed at improving community. This, in turn, involves consensus building, reciprocity, shared needs, and the capacity for collective action [26]. Langerock [27] contends that collaborative processes improve student achievement and improved social skills for all her students.

Cesar and Santos [28] underscores the importance of collaborative practice to inclusive learning; and sustaining transformative action. The positive benefits of effective collaborative practice continue beyond project completion to positively impact ways of thinking, acting and understanding. Collaboration also facilitates student teachers' confidence in challenging preconceived beliefs and perspectives. Wormnaes notes however that the objectives of this collaboration must move beyond the simplistic practices to embrace trust, respect for others, sensitivity and curiosity [29].

\section{Methodology}

Using open-ended qualitative questions, we, the co-researchers, collected the responses of 120 teacher candidates who were responsible for 35 exhibits. Teacher candidates would have collectively in groups ranging from three to five members organized 100 exhibitions of their work across two campuses, and presented over two alternating days.

The assignment involved working in assigned groups to create an information booth and exhibit pertaining to an area of disability. Teacher candidates were expected to ensure: correct information, show evidence of work with related agencies, products that evidenced technology, answer questions by professors and other visitors, and for the classes participating in the study complete an open-ended questionnaire. On the day of the exhibitions, professors were assigned to visit, critique, and grade each exhibition. The open-ended questionnaire included the following:

1. What did you learn about yourself from the assignment? 
2. What do you celebrate most about the assignment?

3. What was the most challenging aspect of the assignment?

4. How did you contribute to the success of the assignment?

5. On a scale of 1-5, [1 poor, 2 minimal, 3 fair, 4, good, 5 excellent], rank the contribution of the other members of the group.

6. Any other comment to help future students completing this assignment.

\subsection{Data sources}

The units of analysis were the comments of participants to six open-ended questions. Responses were analyzed through an inductive process according to Bogdan and Biklen [30]. This process served to identify critical themes and gain insight into the participants' perceptions of and experiences with creating and displaying exhibits. To accomplish this, we collated and typed all written responses to all the open-ended questions. For data analysis we made 4 groups using letters of the alphabet to distinguish quotations. Each co-researcher independently reviewed, and coded the responses for each question on the basis of reoccurring themes. Following independent identification of categories, the co-researchers collaboratively reviewed their findings; further .collapsing these to create the major themes.

\section{Findings}

Over two days at two campuses, there were packed rooms and auditoriums. Faculty, staff, students, voluntary organizations and the public reviewed no less than 100 exhibits, asking questions and making suggestions both in terms of the issues raised for assessment and intervention as well as exhibit design and implementation. Artifacts included but were not limited to:

- $\quad$ Pens and pencils with logos and names of teams

- T-shirts and Polos

- Caps

- Bookmarks

- Note pads and diaries

- Brochures

- Cups and mugs

- Calendars

- DVDs and CDs of information on disabilities

- $\quad$ Magnetized memo holders

The exhibits included DVD and video clips being shown, role-plays of the screening process, presentations, use of consultants from special schools and voluntary organizations. Data analysis overall reveals that the exercise significantly contributed to a sense of satisfaction, community, resourcefulness, professional and social skills development, appreciation of the efforts of others, and a hot list of do's and don'ts for future efforts.

\subsection{Lessons learned}

More specifically, in response to question 1: What did you learn about yourself from the assignment? -- an overall $85 \%$ of participants expressed satisfaction that the assignment, and the required collaboration, contributed significantly to their recognition of their own strengths and weaknesses.. Sixty percent of responses made some reference to being not ready, or feeling ill prepared to take on leadership roles. This was attributed to concerns about imposing their opinions on others, not wanting to appear too pushy, the paucity of information, not knowing enough about their team members, lack of confidence, and feeling overwhelmed with the number of overall assignments they were faced with. Others identified the recognition and emergence of their leadership skills as significant. Some $44 \%$ benefitted by recognizing and developing intrinsic and dispositional factors such as patience, tolerance, confidence, and perseverance. There was also testimony of an increased readiness to overcome obstacles, work under pressure, and to encourage and motivate others among the lessons learned by participants.

Thirty seven percent of respondents of the respondents acknowledged that through group work anything can be accomplished and that hidden creative energy was more readily determined. Among the terms used to evidence these creative energies are the following: the capacity for group work, expressive language, and a recognition that learning need not be classroom based. The responses of $15 \%$ percent of participants claimed that the experience confirmed that they were individualistic, did not increase their content mastery, and preferred to work alone. Four percent emphasized that they learned about the need to take better care of themselves and to experience life more fully.

\subsection{Celebrations}

Regarding question two, (What do you celebrate most about the assignment?) participants found much to celebrate about the experience, with the largest group (35\%) identifying that exhibiting their final product brought them their highest level of satisfaction. A further $25 \%$ identified the group process itself as being the most rewarding. This included getting to know and appreciate their strengths, as well as those of other group-members, and the sense of being a team. 
This activity so early in our university experience proved critical to me ... to us as a class too ... in terms of underscoring the importance of our roles as leaders, followers, and stakeholders in educational problem solving. Woke me up to realizing teacher education ... . my learning to be a teacher . . . is not a passive academic thing. [3F]

Another 25\% identified the search for information and content mastery. They identified activities such as going through archives, meeting special education advocates, interacting with students with disabilities and other related professionals as being the most significant. Fifteen percent of responses focused on experiences shared--

"Great experience"; "It was wonderful . . . visiting and interacting with staff and students from special schools and NGO's. "Great final display”.

\subsection{Challenges}

Question three (What was the most challenging aspect of the assignment?) targeted the challenges of respondents. Thirty-nine percent of responses found that there were significant obstacles to achieving the objective. Particular challenges involved a lack of leadership, finding time to meet, dealing with group dynamics, temper flare ups, 'free riders'.

In our group we were lucky to have hard working members committed to a great exhibit. But the process didn't start of so smoothly. There were fragile egos to contend with. We had to find a balance between the bossy and the ... uh ... minimalist. [2B]

I work hard and I am not known to be patient. I had to really struggle to not take over. [3Z]

While I had ideas, I am not competitive nor am I inclined to argue my position. Especially among strong personalities who are not my friends. So for a bit too long I choose to be quiet and observe.[2AH]

The actual product development and exhibit proved the most stressful for $31 \%$ of the respondents. Among factors contributing to the stress were sourcing and selecting the most relevant material, printing and organizing brochures, and the actual preparation for and presenting of the information.

Oh my gosh. This was so much! Even though our topic was preselected and the group members predetermined, I just didn't know where to start. And no one in my group was willing initially to take charge or at least start to pull things together. [1H]

For another five percent of respondents, event management on the day itself was most challenging. These included: 1) Having to move the display; 2) The booth being located in very sunny area [too hot];
3) Organizing technology use; 4) The late arrival of some group members on display day; and 5) Technological glitches leading to information loss.

\subsection{Contributions}

For question four: (How did you contribute to the success of the assignment?) there were wideranging responses. Forty-five percent of responses claimed that their contributions centered on creativity. These comprised suggestions and help in incorporating technology, printing T-Shirts, developing slide shows and creating power point presentations, printing hand outs, making charts, bookmarks, flyers, posters and brochures. Other important creative contributions included preparing banners, designing logos, and decorating the booths. Thirty percent of responses to question 4 could be grouped into the theme 'research and development'. Visiting schools and NGO's for interviews, access to archives and exposure to real situations were among these research and development activities. Twelve percent of these responses shared that their contributions centered on 'organization'. They emphasized working hard and consistently towards the project goals, motivating team members, keeping team members, on task and maintaining peace and cooperation. Another 12\% determined that their contributions lay in funding and finding sponsorship.

\subsection{Level of Participation}

Responses to question five (On a scale of 1 to 5 rank the contribution of the group members) were concise with few comments added. This dearth of richness was apparent despite the fact that respondents were encouraged to share any additional comments that might show some light into the reasons for their ranking. Fifty three percent gave their members a score of excellent (5); with $25.3 \%$ of the responses - getting 'very good' (4); $10.5 \%$ of the responses 'fair' (3), 6.2\% 'minimal' (2); and 4.9\% of the responses ranked as 'poor'. [1D]

\subsection{Advice}

Finally, with question 6, respondents were invited to share their advice for future students completing this project [Any other comment to help future students completing this assignment?]. Their rich feedback comprised four themes: 1) Organization/Time management, 2) Collaboration, 3) Responsibility, and 4) Attitude.

4.6.1. Organization/Time management. Regarding organization this was singled out, with time management being associated with it. According to 3H: 
Very early ... like immediately upon getting the assignment, you should determine roles and set aside specific dates and time so you can discuss what should be done. [3H]

Y proposed that “. . . start early don't wait for the last minute . . . deadlines for other subjects are around the corner." $2 \mathrm{Z}$ supported this position ...

I began our assignment approximately one and a half months before and we still needed more time although the assignment was excellent [2Z].

Respondents suggested that modeling was an important part of motivating other group members. Individually completing your responsibilities in a timely manner and encouraging discussion on the process allows other group members to further improve on their efforts. [1F]

We are all busy ... . some of us have families and so we have different strategies for getting the job done. Some of us are more product-driven that others. So it is good when those with marketing, p. r. (public relations) and overall organizational experience and high standards in these areas step up show their skills, what they have in mind ... a and to do this early too (laughing). [4H]

While some respondents encouraged modeling, others were less enthusiastic. For example, 2C:

Know what? We come from different situations socially and economically. While it is good to see examples of organizational and time management expertise we can only do so much. While I want to grow professionally and personally I also have a life! We need to have time to relax to. It cannot be all about work. Furthermore, we have other courses with other assignments to complete. So while you work hard also work smart. [2C]

And 2R adds further.

Remember too that collaborative practice is not just about the product -it is about the process. And seeing teachers and professors collaborating is just as important as seeing the products gained from collaborative practice among student teachers. I don't see much co-teaching and collaboration with faculty! [2R]

4.6.2. Collaboration matters. Beyond the issue of time management, organization skills, and modeling, collaboration, and communication emerged as a second theme of advice for future teacher candidates.

Don't think negatively of collaboration. It is good and real. We need to work together. Remember too that collaboration today's age does not always require face-to-face live presence. Use the technology [3T].

Make the maximum use of technology like Skype, BBM, text messaging, Facebook, Google docs to facilitate this ... constantly talk and keep in contact with your group as new ideas may develop that can be significant to the assignment that you would not want to pass up on. [2V]

Successful collaboration involves also being sensitive to other members.

Make sure you come together or collaborate as a group and not leave out any members. Be sensitive to how we tend to only communicate with the sisters or the clique and when we have others who do not belong to our social or academic or even ethnic and religious group for those of us who are so inclined we leave them out for later. Sometimes we are closer to those we share other courses and assignments with. Try to involve everyone when coming to exchanging information and ideas, and especially when it has to do with money and fund raising. $[4 \mathrm{X}]$

Future teacher candidates were encouraged to be frank and open in asking questions and voicing concerns or suggestions. We were reminded that collaboration thrives on openness that is immersed in respect and staying focused on the objective. One student shared that identifying former students who might have completed a similar assignment and gaining their advice worked for her. [2I]

I was advised to determine the specific objectives of the assignment, start planning early ... not take differences of opinions personally . . . and to keep a log of my responsibilities.

A spiritual dimension was also suggested in the recommendations that encouraged the use of prayer, as illustrated by:

You'll be surprised to know how starting your group meeting with a sincere inter-religious prayer can keep people focused. [4K]

A short non-denominational word [of prayer] reminds us of the higher calling that is teaching. It reminds us of the mission that we are being prepared for. [2SD]

4.6.3. Responsibility. Respondents urged future teacher candidates to see the clear relationship with the assignment and their own professional development.

Take your assignment seriously. Learning how to identify sources of information, collecting the information, determining what's critical, and presenting that to a critical audience all reveal your sense of responsibility. These are wrapped up in the assignment! All these shape your professionalism and effectiveness'. [3AM].

Others linked responsibility to the team, the group, and the role of advocacy. 
... as future teachers it is our responsibility to make the public aware of these disabilities. That's all part of the job of being a special education teacher. [1AR]

Effective teaching is about all students regardless of differences and abilities. That's a big responsibility. That's why we are here at university. [2H]

4.6.4. Attitude. Being positive and realizing that there is a relationship between attitude and success both in terms of the assignment and one's overall professional development summarizes the contributions of these participants. Popular words used were 'resilience', 'persistence', 'Enjoying the process and the product'. 3T observes:

I would encourage future students to view this assignment with an extra amount of joy. If you view the assignment as a task or for course marks, the value of the project and the related

\section{Discussion} research will be lost. [3T]

Overall participants shared important benefits in mastery of course content, and personal/professional development. The latter includes communication, shared problem solving, time management, and collaborative practice.

Respondents, while celebrating the lessons learned, acknowledged challenges related to interpersonal and leadership style, communication skills, scheduling and time management, work ethic, and the role of prior school experiences in preparing them for their roles as team players. Respondents also felt that too often leadership and individual responsibility were lacking from peers. More, they contend, could be done to help them become members of a collaborative community.

Hopkins, Beresford, and West [31] support this position, contending that teachers are more apt to assume collaborative roles when the community itself reflects such a culture. Since collaboration cannot be mandated nor imposed, we as teacher educators should aim to develop assignments that involve collaborative practice and the democratic process [32]. As Friend and Bursuck assert collaboration is a process to be facilitated [33]. Beginning teachers thus build collaborative skills along with higher levels of resiliency, flexibility, and innovation.

A further dimension that emerged was the candidates' perceptions of disabilities. This was not originally a focus of the study. A majority of candidates shared that the assignment and the experience of collaboration broadened their understanding of disability and inclusive education. In Trinidad and Tobago, as part of the global phenomenon, teachers are being challenged to adopt more inclusive practices. Indeed, they are expected to broaden their mostly cautious attitudes by extending their notion of inclusion from disability to difference [34].

This underscores the importance of teacher preparation in using information and field based opportunities to address the attitudes of pre-service teachers. Further, an even greater challenge for today's teacher educators may be to effect positive attitudinal change [35]. The future of inclusive education may be dependent upon thoughtful practitioners whose beliefs and actions not only are verbalized, but also are demonstrated. We note that not all participants, $20 \%$, indicated no or negative changes in their attitudes. Among the statements we attribute to positive change were the following:

- Compelled me to re-examine my own beliefs about disability as defects, deficits. [1C]

- We did it!! At first I thought this assignment was an impossibility. Now I feel more confident in myself and what could be accomplished. [1H]

- $\quad$ increased my awareness of the range of complexity and uniqueness within areas of disability. [1S]

- Made me question my role as a teacher-much different from what I anticipated. [2SD]

- I saw the important role of the voluntary agencies and institutions involved with disabilities. [2Z]

- I am challenged. I feel as if I have a mission to serve as an advocate. [3F]

- This was about my brother ... who is disabled. [4S]

- The assignment allowed us to share the concerns and voices of family members who care for or have special needs. disabilities. [4W]

These indicators support the position that the experiences of project and problem based learning affect teacher attitudes; which might be one of the most influential variables in the success of inclusion initiatives [33]. 


\section{Recommendations}

These include reviewing the present assignment to include more service learning, community and advocacy centeredness, a comprehensive rubric, and a more coherent system of group determination. We propose also to have candidates select their group leaders who in turn should be able to access basic leadership skills training, support, and related guidelines from faculty associated with the project.

\section{Conclusions}

We consider this project to be quite a success. It has contributed toward developing teacher candidates' appreciation and knowledge of disabilities, challenged their notions on inclusive practice, and developed their leadership and followership skills and self-confidence. The campus and broader community have benefited from partnership with teacher candidates; who have themselves benefited from the opportunity to engage in various voluntary and professional communities beyond the campus' classroom. The assignment provided purposeful learning, information gathering and sharing, leadership, and advocacy skills. We note however, a need to further probe the teacher candidates' understanding of the role of collaboration within the local teaching/learning context. Also, we must consider how to encourage more creative and robust ways of sharing information and building collaborative teams. We plan to explore these in future.

\subsection{Significance of the study}

The study offers an opportunity for faculty to review and revise curricula that will further engage teacher candidates and facilitate improved professional development. As a fledging institution, review and evaluation is critical to program development at UTT. Strategies that address emergent problems and enhance the exhibit will go a long way to ensuring appropriate educational reform.

\section{References}

[1] H. Manning, "Remarks by Senator Hazel Manning on the occasion of the workshop to facilitate the design of a seamless education system project for Trinidad and Tobago", 2007. Retrieved June 2011 from: http://www.moe.gov.tt/Docs/Speeches/2007/SeamlessEduc ation.pdf

[2] D. A. Conrad, and Brown, L. I. "Fostering inclusive education: principals' perspectives in Trinidad and Tobago". International Journal for Inclusive Education, In Press, 2010
[3] UNESCO and Information Literacy. Retrieved May 2011, http://portal.unesco.org/ci/en/ev.phpURL_ID=27055\&URL_DO=DO_TOPIC\&URL_SECTIO $\mathrm{N}=201 . h \mathrm{tml}$

[4] U.S. National Commission on Library and Information Science, "The Prague declaration: Towards an information literate society”, 2003,

http://www.nclis.gov/libinter/infolitconf\&meet/postinfolitconf\&meet/PragueDeclaration.pdf

[5] American Association of School Libraries, "Standards for the 21st century learners”, Retrieved October 2009, 'http://www.ala.org/aasl/standards

[6] L.J. Chan-Lin, Technology integration applied to project-based learning in science, Innovations in Education and Teaching International 45, 2008, pp. 55-65.

[7] Harada, V., C. Kirio, and S. Yamamoto, Collaborating for project-based learning in grades 9-12, Linworth Publishing, Worthington, OH, 2008.

[8] L. Bowler, A. Large and G. Rejskind, Primary school students' information literacy and the web, Education for Information 19, 2001, pp. 201-223.

[9] R.F. Owens, J.L. Hester and W.H. Teale, Where do you want to go today? Inquiry-based learning and technology integration, Reading Teacher 55, 2002, pp. 616-625.

[10] R.W., Marx., P.C. Blumenfeld, J. S. Krajcik, M. Blunk, and B. Crawford, "Enacting project based science: Experiences of four middle grade teachers”, Elem. Sch. J., 1994, pp. 517-538. Retrieved May 2011 http://www.jstor.org/pss/1001840

[11] Holubova, R., Effective teaching methods project-based learning in physics. US-China Educ. Rev., 5: 27-36. 2008.

[12] M. Panasan and P. Nuangchalerm, Journal of Social Sciences 6 (2): 252-255, 2010.

]13] Larmer, J. and Mergendoller, J. R., Educational Leadership, 68, 1, 2010, pp34-37.

[14] Thomas, J. W., Mergendoller, J. R., \& Michaelson, A. Project-based learning handbook for middle and high school teachers. Buck Institute for Education, Novato CA. 1999.

[15] D. Bilal, "Children's use of the Yahooligans! web search engine II: Cognitive and physical behaviors on research tasks", Journal of the American Society for Information Science and Technology 52, 2001, pp. 118136

[16] R. M. Wallace, Kupperman, J., Krajcik, J., and E. Soloway, "Science on the Web: Students online in a sixthgrade classroom”, The Journal of the Learning Sciences 9 (1), 2000, pp. 75-104. 
[17] Dewey, J. How we think, Lexington MA, D. C. 1910.

[18] Piaget, J. Equilibrium of cognitive structures, New York: Viking Press, 1977.

[19] Vygotsky, L.V. Thought and Language (translators. Hamfnann, E. and Vakar, G.). MIT Press and Wiley, Cambridge, Massachusetts, 1962.

[20] Gagnon, G. W. and Collay, M. Constructivist Learning Design-key questions for teaching to standards. Sage, 2005

[21] Jenkins, A., and Sheehey, P. "Implementing Service Learning In Special Education Coursework: What We Learned”. Education, 129(4), 2009, pp. 668-682.

[22] Schon, D. A. The Reflective Practitioner: how professionals think in action, London: Temple Smith, 1983.

[23] Conrad, D., and D. Hedin, "School-based community service: What we know from research and theory", Phi Delta Kappan, 72(10), 1991, pp. 743-749.

[24] J. Mayhew, and Welch, M., “A call to service: service learning as a pedagogy in Special education programs". Teacher Education and Special Education, 24(3), 2001, pp. 208-219.

[25] Dudderar, D. and L. T. Tover, L.T., "Putting Service Learning Experiences at the heart of a teacher education curriculum”, Educational Research Quarterly, 27(2), 2003, pp. 18-32.

[26] H. A. Lawson, "Pursuing and securing collaboration to improve results”. In M. Brabeck, M. Walsh, \& R. Latta. (Eds.), Meeting at the hyphen, 102nd Yearbook of the National Society for the Study of Education Part 11, University of Chicago Press, Chicago, 2003, pp. 45 - 71.

[27] N. L. Langerock, "A passion for action research: Collaboration in an inclusive classroom", Teaching Exceptional Children, 33(2), 2000, pp. 26- 34.

[29] M. Cesar and N. Santos, N., "From exclusion to inclusion: Collaborative work contributions to more inclusive learning settings." European Journal of Psychology of Education, 21(3), 2006, pp. 333-346.

[29] Wormnaes, S., "Cross-cultural collaboration in special teacher education: An arena for facilitating reflection?" International Journal of Disability, Development and Education, 55(3), 2008, pp. 205-225.

[30] Bogdan, R.C. and S. K. Biklen, Qualitative research for education: An introduction to theory and methods. Ally \& Bacon, Needham Heights, MA, 1998.

[31] Hopkins, D., Beresford. J., and M. West, "Creating the conditions for classroom and teacher development." Teachers and Teaching: Theory and Practice, 4, 1, 1998, pp.115-141.

[32] D, Piercey, Why Don't Teachers Collaborate, Phi Delta Kappan, 2010, 92, 1, pp.54-56.
[33] Friend, M. and Bursuck, W. Including Students with Special Needs: A Practical Guide for Classroom Teachers, 6e, Prenhall, 2011.

[34] Conrad, D., Fraser, N., Bruce, M., Fraser. S. and Felix, K. "The Search for Social Justice In Trinidad and Tobago: Perspectives From Two marginalized Contexts". Caribbean Curriculum, 2010.

[35] C. Forlin, Loreman, T., Sharma, U. and Earle, C. "Demographic differences in changing pre-service teachers' attitudes, sentiments, and concerns about inclusive education", International Journal of Inclusive Education, 13, 2, 2009, pp. 195-209. 